Bol. Acad. peru. leng. 66. 2019 (113-140)

\title{
LA INFLUENCIA DEL MEDIO EN LA CONCEPCIÓN DEL DISCURSO: UN ANÁLISIS A PARTIR DE LAJUNCIÓN SINTÁCTICA
}

\section{THE INFLUENCE OF THE ENVIRONMENT IN THE CONCEPTION OF THE SPEECH: AN ANALYSIS FROM THE SYNTHETIC JUNCTION}

\author{
Úrsula Hernández Patrón \\ Pontificia Universidad Católica del Perú \\ Universidad de Piura
}

\section{Resumen:}

El objetivo de este trabajo, cuyas ideas fueron inicialmente publicadas en mi tesis de maestría en Lingüística (2017), es demostrar el importante efecto que el medio o canal tiene sobre las características lingüísticas de los discursos, lo cual difiere de la propuesta por Koch y Oesterreicher en su texto Lengua hablada en la Romania: español, francés, italiano (2007). Esta demostración se logrará a partir del análisis de los mecanismos de junción, propuestos por Raible (2001, 1992), manifestados en las noticias de la versión digital del diario peruano El Comercio, específicamente, aquellas en las que se da un paso explícito del medio fónico al medio gráfico. Para ello, se tuvieron en cuenta noticias de la publicación digital del diario El Comercio que presentan material audiovisual y su respectiva redacción. Los mecanismos de junción serán 
presentados y analizados a partir de una muestra ilustrativa para poder identificar cómo son aplicados por los redactores de las noticias al momento de redactarlas. Los resultados muestran que se suelen utilizar mecanismos de junción con el propósito de condensar las proposiciones al momento de redactar la noticia a pesar de que ambas situaciones presenten características similares de formalidad, lo que indica que el medio es relevante para definir la concepción de un texto.

\section{Abstract:}

The purpose of this study is to demonstrate the important effect that the medium has on the features of the linguistic products, which differs from de proposal made by Koch and Oesterreicher in their text lengua hablada en la Romania: español, francés, italiano (2007). This demonstration will be achieved from the analysis of the most frequently used junction techniques, proposed by Raible (2001:1992), in the news published in the digital versión of the peruvian newspaper El Comercio, specifically those that were initially manifested by the phonic medium and then passed to the graphic médium. To achieve that, we considered news that present audiovisual material with their respective written material. The junction techniques will be presented and analyzed from an illustrative sample to identify how are these mechanisms used when the news were transferred from one medium to the other. The results show that the junction techniques are regularly used by the writers in their texts with the purpose of uniting clauses, wich shows that the medium is important to define the concept of a text.

Palabras clave: sintaxis; junción; medio; texto; prensa digital; El Comercio.

Key words: syntax; junction; medium; text; digital press; El Comercio.

Fecha de recepción:

Fecha de aceptación:
$15 / 09 / 2019$

$31 / 11 / 2019$ 
https://doi.org/10.46744/bapl.201902.005

\section{Introducción}

Es esperable que las personas adapten su modo de expresarse a la situación comunicativa en la que se encuentran. Esta competencia ha sido adquirida gracias a que han logrado reconocer las costumbres y los modos tradicionales de configurar los discursos que forman parte de la sociedad en donde se desenvuelven. Esto genera que los individuos produzcan distintos estilos de discursos adecuados para el contexto en el que se lleva a cabo la interacción, por ejemplo, con rasgos de formalidad, coloquialidad o informalidad, entre otros.

De acuerdo con las situaciones comunicativas, los emisores concretizan sus discursos a través de un canal, como puede ser el papel, las ondas sonoras o un medio digital, por ejemplo. Este canal determinará si el emisor manifiesta el mensaje por el medio fónico, perceptible para el receptor por el sentido del oído o por el medio gráfico, perceptible para el receptor por el sentido de la vista. El medio a través del cual se concretiza el discurso va a ser determinante también en el modo en que este sea elaborado. Esto se debe, entre otras cosas, a que la graficación del discurso, es decir, su redacción, ofrece también la oportunidad de planificación y corrección, sin que quede huella alguna del proceso. Por el contrario, no cuentan con dicha ventaja quienes van elaborando el discurso a través del medio fónico, debido a que el proceso se está llevando a cabo en el mismo momento en que está siendo percibido por el interlocutor.

En relación con lo dicho, en el presente trabajo examinaremos los mecanismos utilizados en la construcción de enunciados al momento de graficar o redactar un discurso emitido originalmente por el medio fónico. Busco analizar los discursos que corresponden a una misma noticia, pero que han sido concretizados por dos medios distintos: fónico y gráfico. Inicialmente, las noticias extraídas de la versión digital del diario El Comercio y aquí analizadas son entrevistas emitidas por video, y luego estas mismas noticias son redactadas a partir de citas que se entienden como textuales, por el uso de las comillas; sin embargo, a pesar de utilizar el típico formato de cita directa o textual, muchas veces, el redactor opta por realizar cambios al momento de graficar la noticia. 
En las noticias revisadas, busco analizar los cambios producidos en el nivel de la sintaxis, específicamente los mecanismos de integración de unidades lingüísticas, los cuales son propios de la dimensión junción, al momento en que se cambia el medio. El objetivo es demostrar la fuerte influencia que la realidad extralingüística, que involucra a la situación y al medio, tiene sobre la elaboración de los enunciados lingüísticos en la medida en que estos últimos están inmersos en actividades comunicativas concretas.

Para lograr el objetivo del trabajo, primero realizaré una breve descripción de la teoría que ha sido medular para el análisis: la distinción entre medio y concepción planteada por Koch y Oesterreicher. En la segunda sección, brindaré una breve explicación del objeto de estudio y del tipo de noticias que han sido elegidas para ser analizadas. Luego, presentaré el fenómeno sintáctico elegido para el análisis de la muestra, la dimensión junción. Seguido de ello, analizaré los hallazgos del paso del medio fónico al medio gráfico en las noticias seleccionadas. Finalmente, en las conclusiones, detallaré los resultados obtenidos a partir del análisis de la dimensión junción para brindar una breve explicación sobre la influencia del medio en la concepción del discurso.

\section{Estado de la cuestión: la teoría de Koch y Oesterreicher}

Para abordar esta investigación, me he basado en los estudios sobre la diferenciación dicotómica entre el medio y la concepción de los discursos propuesta por los autores Koch y Oesterreicher en su publicación Lengua hablada en la Romania: español, francés, italiano (2007).

Peter Koch y Wulf Oesterreicher plantean la distinción entre las nociones de medio y concepción, esenciales para la presente investigación, al inicio de su libro Lengua hablada en la Romania: español, francés, italiano del siguiente modo:

Para el neófito, pero también a menudo en la propia ciencia lingüística, los términos «hablado» / «oral» $\mathrm{y}$ «escrito» / «escritural» designan en primera instancia la realización material de expresiones lingüística, es decir, el 
hecho de que éstas se manifiesten, bien en la forma de sonido (fónica), bien en la forma de signos escritos (gráfica). Sin embargo, por mucho que la justificación de esta diferenciación sea evidente, por sí misma no da cuenta de la compleja problemática de la oralidad / escrituralidad. Todos conocemos expresiones realizadas fónicamente, cuya configuración lingüística apenas se corresponde con nuestra intuición de la oralidad (por ejemplo, oraciones fúnebres, explicaciones durante una visita guiada por un castillo o un pregón de fiestas). Por otra parte, también hay expresiones realizadas gráficamente que difícilmente coinciden con nuestra idea de escrituralidad (por ejemplo, notas o apuntes de clase, los bocadillos de los cómics o una carta privada) (2007: 20).

Es así que, para los autores, el medio, o realización material del discurso, no determina necesariamente la concepción de este. La concepción, desde el punto de vista de la teoría presentada, refiere a la configuración lingüística de la expresión, la cual se vincula directamente con los estilos de lengua empleados (Koch y Oesterreicher 2007: 21).

Desde el punto de vista de los autores, los términos oral y escrito no refieren a medios de materialización del discurso, sino que se utilizan para categorizar concepciones diferentes de discursos. Tal como lo explica Ricardo Renwick:

La diferenciación introducida entre los criterios medial y concepcional supone un afinamiento en la observación y descripción de las relaciones entre la lengua hablada y la lengua escrita. Si bien se impone a primera vista el hecho de que la lengua escrita y la lengua hablada se vinculan al medio gráfico y al medio oral, respectivamente, no es menos cierto, por otro lado, que determinadas manifestaciones escritas presentan rasgos que podrían ser identificados como pertenecientes al dominio de la oralidad. Tomemos por ejemplo el caso de la reproducción gráfica de una entrevista. Aunque en ella se ha hecho uso del medio gráfico, es obvio que en el plano concepcional su modalidad de verbalización se corresponde en parte con los rasgos normalmente atribuidos a la oralidad. El caso contrario no es extraño si pensamos, por ejemplo, en una conferencia: su realización es evidentemente oral, pero su volumen de información y su grado de elaboración serían adscritos sin muchas reservas a la escrituralidad (1997: 23). 
Para poder identificar cómo debe ser la configuración de un discurso, Koch y Oesterreicher plantean parámetros graduales que ayudan a determinar los distintos tipos de situaciones comunicativas. Es así que consideran situaciones ubicadas en un continuo que presenta, en un polo, la inmediatez y, en otro, la distancia, los cuales corresponden con los polos concepcionales de oralidad y escrituralidad, respectivamente. Es decir, en una situación de distancia se configuran discursos con rasgos escriturales, mientras que, en una situación de inmediatez se configuran discursos con rasgos más orales, independientemente de cuál sea el canal o medio de trasmisión del mensaje.

Koch y Oesterreicher (2007: 26-27) proponen los siguientes parámetros para caracterizar los distintos tipos de condiciones comunicativas que rigen la concepción de los actos comunicativos lingüísticos; es decir, los autores plantean características de naturaleza extralingüística que determinarán la formulación de los discursos:

a. Grado de publicidad, vinculado con el carácter más o menos público de la comunicación;

b. Grado de familiaridad entre los interlocutores, depende del conocimiento compartido y experiencia comunicativa conjunta previa;

c. Grado de implicación emocional, puede estar regido por el interlocutor o por el referente de la comunicación;

d. Grado de anclaje de los actos comunicativos en la situación y en la acción;

e. Campo referencial, refiere a la distancia de los referentes de la comunicación respecto del hablante;

f. Inmediatez física de los interlocutores, distingue la comunicación cara a cara frente a la de distancia física y temporal;

g. Grado de cooperación, relacionado con la intervención de los receptores;

h. Grado de dialogicidad, se vincula con el intercambio de roles comunicativos;

i. Grado de espontaneidad de la comunicación; 
j. Grado de fijación temática.

Según los autores, y teniendo en cuenta los parámetros presentados, los hablantes configuran sus discursos aplicando ciertas estrategias de verbalización, las cuales constituyen respuestas lingüísticas a las situaciones comunicativas en las que se encuentran inmersos. Las estrategias de verbalización se vinculan con la formulación del material lingüístico. Estas son las que les brindan las características concepcionales a los enunciados. Koch y Oesterreicher (2007), Oesterreicher (1997) y Renwick (1997) postulan que las estrategias de verbalización de los discursos originados en inmediatez comunicativa se vinculan con un bajo grado de planificación y estructuración por el hecho de que los discursos están siendo construidos en el mismo momento de su manifestación. También, en los discursos emitidos en situación de inmediatez comunicativa se encuentra una preferencia por procedimientos agregativos. Por otro lado, respecto de las estrategias de verbalización de los discursos originados en la distancia comunicativa, estas suelen ser de una mayor planificación y presentan una verbalización compacta e intensiva, por lo que construyen relaciones sintácticas más complejas y de tipo integrativo.

\section{Metodología}

\subsection{Objeto de estudio}

Las noticias publicadas en el diario El Comercio desde su primera edición, en mayo del año 1839, se han caracterizado por presentar rasgos escriturales. Esto se debe a que presentan parámetros propios de una situación comunicativa de distancia, lo cual es común entre los medios de prensa formales de nuestra sociedad.

Como se indicó anteriormente, los discursos de la distancia comunicativa manifiestan un grado de planificación alto, lo que implica una mayor elaboración. Esto se confirma en la cita presentada a continuación:

Ante su máquina de escribir, con los apuntes que haya hecho previamente, el reportero empieza a redactar su información. Sabe ya, puesto que la 
ha trabajado, si será de exposición e interpretación o simplemente una crónica de lo que haya ocurrido. Si lo que necesita hacer es explicar, sabe por experiencia que toda exposición demanda un plan bien definido y que el tiempo que emplee en hacer un bosquejo lo ahorrará con creces cuando empiece a escribir en firme. La claridad es el fin que se persigue en toda explicación. Por muy detallada y erudita que la explicación sea, si deja al lector confuso o desorientado, esa explicación podrá ser considerada como mala. La única forma de evitar una información confusa es trazando antes un plan de exposición (Bond 1965: 127).

La publicación impresa del diario El Comercio sigue circulando diariamente a nivel nacional. En adición a esta, desde el 15 de enero del año 1997, también se publica en versión digital, formato que es considerado «una versión ágil, veraz e independiente, actualizada minuto a minuto» (El Comercio, 1997: 104). Esta relativamente nueva versión presenta información bastante similar a la de la impresa y, a pesar de presentar características del periodismo digital, como lo es la posibilidad de que los lectores tomen un papel más activo al momento de enfrentarse con la noticia, o la velocidad y el modo en que las publicaciones son generadas, los redactores tratan de mantener el estilo que siempre caracterizó a El Comercio en la edición impresa. Esto sigue siendo posible, ya que aún tienen la oportunidad de sentarse frente a la computadora a redactar la noticia, lo que les brinda la oportunidad de pensarla, planificarla y configurarla, a diferencia de quienes emiten la información por medio fónico. La distinción se relaciona, como se señaló anteriormente, con el hecho de que este último tipo de emisión se da en tiempo real, lo cual ocasiona que las estrategias de verbalización no puedan ser totalmente afines a las de la distancia comunicativa, como lo son en el caso de las noticias por medio gráfico presentadas en el formato digital.

\subsection{Descripción y selección de la muestra}

Las noticias elegidas para el análisis son multimediales, ya que combinan video con texto redactado, lo cual significa que dentro de una misma noticia encontramos dos tipos de discursos: uno emitido 
https://doi.org/10.46744/bapl.201902.005

a través del medio fónico (en el video) y otro manifestado por medio gráfico (en la redacción de la noticia). Estas han sido tomadas de la versión digital del diario El Comercio. Se ha optado por que ambos contenidos, tanto la redacción como el video, sean producidos por el mismo diario. A partir de ello, haré una comparación entre las dos partes de la noticia, el contenido audiovisual y el redactado, para poder identificar los mecanismos y procesos de junción que generan un cambio en la concepción del discurso al momento de cambiar de medio.

El corpus para el análisis de la presente investigación ha sido tomado de la sección Economía del diario, la cual, tanto en la versión digital como en la impresa, presenta noticias de temas económicos y de negocios. Por ser una sección relevante para el diario, ya que se publica diariamente en ambos formatos, fue considerada como significativa para extraer el corpus de la presente investigación. Decidí trabajar solo con la sección mencionada de El Comercio para que el estilo en el que se presenta la noticia sea similar en todo el corpus. Por el tipo de temas que se presentan en dicha sección, sus discursos tienden más a los que se vinculan con una situación de distancia comunicativa y son concebidos como más escriturales.

Por otra parte, al seleccionar las noticias multimediales (una modalidad que presenta un material audiovisual y su respectiva redacción) que forman parte de la sección del diario también, consideré que cumplieran con determinados criterios. En primer lugar, las noticias deben de presentar la cuña de El Comercio necesariamente, lo cual evitará que se trabaje con un material audiovisual editado por un medio de comunicación distinto. En segundo lugar, consideré pertinente que quienes se presenten en el video sean personas que no evidencien rasgos de pronunciación o gramática de una lengua distinta del español para que los cambios llevados a cabo por el redactor, con el objetivo de lograr una mejor comprensión, no sean motivados por el hecho de presentar una gramática que siga la estructura del español estándar; ya que dicho cambio no se vincularía con lo referente al medio y se apartaría del objetivo de la presente investigación. 
En tercer lugar, los videos seleccionados son los que se encuentran en un ambiente de entrevista tranquilo, es decir, donde el entrevistado tiene la posibilidad de responder calmado directamente al periodista del diario. Esto se debe a que, en entrevistas espontáneas, el apuro pueda conllevar que el discurso presente más rasgos de oralidad que las otras noticias de la sección Economía.

En cuarto lugar, he tomado como muestra específicamente los fragmentos que hayan sido graficados como cita directa o discurso directo - es decir, los que presenten las marcas tipográficas que delimitan este tipo de cita (entre comillas) — y la correspondiente emisión fónica del entrevistado tomada del video de la noticia. Para ello, en la sección de análisis del trabajo se realizarán transcripciones de los fragmentos fónicos que correspondan. He considerado este criterio para el análisis, debido a que llama la atención que se use el formato de presentación de cita textual cuando no necesariamente se presentará una cita textual típica; ya que no siempre las noticias emitidas por el medio fónico han sido reproducidas textualmente en las redacciones. Como sabemos, una cita textual es la reproducción literal de las palabras expresadas en un discurso previo al que se está emitiendo. Es así que, si la reproducción es literal, lo esperable es que el periodista, al redactar la noticia que se presenta de modo audiovisual por el medio fónico, debería reproducirlo fielmente. Sin embargo, a pesar de que las comillas estén presentes, esto no siempre sucede.

Es importante tener en cuenta, además, que el uso de comillas para marcar cita directa o textual es un recurso bastante común en la redacción de entrevistas (Gargurevich 1989: 44), por lo cual es esperable que, en las noticias analizadas, ya que surgen a partir de entrevistas, muchos de los fragmentos se encuentren entrecomillados.

\section{Mecanismos de conexión sintáctica: la dimensión junción}

La relación y conexión que se da entre las palabras que conforman frases u oraciones es estudiada por el nivel sintáctico de la lengua. La dimensión junción, al ser una técnica de relación entre los enunciados, forma parte de lo estudiado por la sintaxis. 
https://doi.org/10.46744/bapl.201902.005

Ricardo Renwick (2006) explica el concepto de junción desarrollado por Wolfgang Raible (1992), para comprender los fenómenos de conexión y complejidad sintáctica. La junción se da entre dos estados de elementos o situaciones extralingüísticas representados en dos estructuras lingüísticas o sintácticas. Es así que, al crear un discurso, los hablantes se valen de una serie de técnicas de relación de signos lingüísticos ofrecida por el sistema de la lengua para conectar los estados de cosas en forma lingüística.

Los conceptos esenciales para comprender la dimensión junción son la agregación y la integración. "Las características más relevantes son, para el caso de la agregación, una estructuración de tipo paratáctico y un bajo grado de cohesión sintáctica. En el caso de la integración, por el contrario, se da un tipo de estructuración más bien sintáctico (en el sentido estricto de conexión explícita a que nos remite el término sintaxis), razón por la cual también se puede verificar un mayor grado de cohesión sintáctica» (Renwick, 2006: 279). Por la complejidad respectiva de las conexiones agregativa e integrativa, y relacionando ambas con las estrategias de verbalización mencionadas previamente, se puede establecer que los discursos escriturales presentan más a menudo conexiones integrativas; mientras que los discursos de concepción oral, conexiones agregativas.

La integración se evidencia en el uso de las nominalizaciones, que se consideran el mecanismo integrativo más característico. Estas representan el paso de una estructura verbal a una sustantival. El volver sustantivo a un verbo determina su inserción en una misma unidad temática, ya que, de esa manera, pasa a ser un argumento de la predicación principal. Por otro lado, la conversión del verbo en participios o en infinitivos también determina que este sea usado sintácticamente como un adjetivo o como un sustantivo, respectivamente, lo cual también contribuye a integrar la unidad temática. Asimismo, la subordinación de oraciones también es una estrategia de un tipo de conexión más integrativo a diferencia de la unión por coordinación, por ejemplo, con el uso del morfema gramatical libre $y$. A diferencia de ello, por ejemplo, la lengua oral es más fragmentada y muchas veces carece de un nexo explícito que relacione los enunciados; por ello, se la considera más agregativa. 
Como se pudo comprender de la cita de Renwick presentada líneas arriba, dos conceptos esenciales para la comprensión de los mecanismo agregativos e integrativos: la parataxis y la hipotaxis. Se suelen vincular los términos coordinación con parataxis y subordinación con hipotaxis. Ángel Lopez (2000) señala lo siguiente al respecto: «[...] en la unión de frases la coordinación se caracteriza porque ninguna de ellas conlleva semánticamente la presencia de la otra, mientras que, en la subordinación, la subordinante implica un significado que encarna la subordinada, si bien, en algunos casos, permanece implícito» (3516). Es decir, «[...] la coordinación no supone implicación de unos elementos respecto de otros, la subordinación se basa en que el elemento dominante implica las características semánticas del dominado» (3517). Así pues, con esta cita se busca explicar claramente que la subordinación es más integrativa que la coordinación.

Entonces, la subordinación o bipotaxis, al ser un mecanismo de conexión que implica mayor integración, será más propia de los discursos escriturales que de los orales debido a su complejidad, mientras que la coordinación o parataxis, por ser más agregativa que integrativa y, por ello, menos compleja, sería propia de discursos más orales. A pesar de ello, no es poco común que, en los discursos propios de la oralidad también se encuentren presentes mecanismos hipotácticos muy sencillos, como lo son el uso de relaciones causales o cuando un verbo principal constituye el antecedente de una subordinada, la cual también constituye el antecedente de otra subordinada. Sin embargo, en los discursos propios de la distancia comunicativa hay integración, pero también condensación. El mecanismo de recursividad de la lengua hablada no evidencia esta última característica.

Raible ha propuesto grados de agregación y de integración en el marco de la dimensión junción, estableciendo las categorías aquí presentadas. Los ejemplos fueron tomados de Jungbluth (1996: 345).

1. Yuxtaposición simple sin junción cualquiera (por ejemplo: Mercé tiene fiebre. No va al colegio.)

2. Junción mediante referencia explícita de una parte de la frase anterior (por ejemplo: Mercé tiene fiebre. Por eso no va al colegio.) 
https://doi.org/10.46744/bapl.201902.005

3. Frases coordinadas explícitamente (por ejemplo: Mercé no va al colegio ni tiene fiebre.)

4. Junción por medio de conjunciones subordinantes (por ejemplo: Mercé no va al colegio porque tiene fiebre.)

5. Gerundios y participios (por ejemplo: Atacada por la fiebre, Mercé no va al colegio.)

6. Grupos nominales que suelen dominar una construcción nominal o una construcción con el verbo infinitivo (por ejemplo: Por causa de la fiebre, Mercé no va al colegio.)

7. Preposiciones simples y/o morfemas de caso (por ejemplo: Por fiebre Mercé no va al colegio.)

8. Los actantes (por ejemplo: La fiebre impide la presencia de Mercé en el colegio.)

Según lo planteado por Raible, se considera que a partir de la categoría número 4 ya se pasa del principio de la agregación al principio de la integración. A medida que se avanza en las categorías, el grado de integración se incrementa.

Quien emite un discurso con rasgos de oralidad tiende a recurrir a nexos coordinantes para expresar oraciones complejas; esto significa que no siempre se utilizan los nexos siguiendo su significado tradicional. Por ejemplo, se dan casos en los que se utiliza la conjunción $y$ para establecer un contraste, o la conjunción pero en un contexto no contrastivo, en el cual simplemente funciona como un conector no específico. Otra conjunción subordinante que pierde su semántica fácilmente en la lengua oral es que, debido a que, muchas veces, se vacía semánticamente y pierde su función gramatical tradicional (Vigara Tauste, 1992: 123-127). Esto no suele ocurrir en los discursos de distancia comunicativa, ya que, como señalan Koch y Oesterreicher (2007), «en condiciones de distancia comunicativa priman distintos tipos de procedimientos cuyo objetivo es hacer que la fuerza ilocutiva de una expresión y sus eventuales matices sean lingüísticamente lo más explícitos posibles» (96).

Es decir, los hablantes reaccionan a las condiciones comunicativas resultantes de la relación entre parámetros y contextos recurriendo a 
distintas estrategias de verbalización (Renwick, 1997: 26). Por ejemplo, las situaciones comunicativas de distancia requieren de estrategias de verbalización muy cuidadas. Debe haber una planificación exhaustiva del discurso, así como el empleo de un lenguaje formal, y una sintaxis completa y compleja: sin cortes y, preferiblemente, integrativa. Por otro lado, no se espera que en una conversación espontánea entre amigos, ya sea a través del medio fónico o del medio gráfico, típica de una situación que cumpla con los parámetros de la inmediatez comunicativa, el lenguaje sea tan cuidado, que haya un grado alto de planificación del discurso ni que se presente un tipo de sintaxis compleja; ya que la vinculación con el contexto situacional tiene un rol importante en la compresión del enunciado (Koch y Oesterreicher, 2007).

Es importante tener en cuenta que en los discursos de distancia comunicativa se presentan, con relación a la sintaxis, «unidades compactas y fuertemente cohesionadas, en las que es posible observar un mayor aprovechamiento de las posibilidades que brinda el sistema, de ahí que se caractericen por su gran volumen de información lingüística y por su alto grado de complejidad y planificación» (Renwick, 1996: 275), a diferencia de lo que se ve en los discursos de inmediatez comunicativa. En las situaciones comunicativas de distancia, el emisor tiene mayor opción de integrar una sucesión de ideas en una unidad temática completa, compleja y condensada; esto se debe a que, al comunicarse a través del medio gráfico, el emisor dispone de mayor tiempo para formular su discurso, lo cual implica que tiene mayor opción de integrar una sucesión de ideas organizada en una unidad temática. Ello da como resultado un discurso más integrativo en comparación con el que se da en el medio fónico.

\section{Análisis de los datos}

En el presente capítulo, analizaré las noticias representativas escogidas para ejemplificar y evidenciar la escrituralización de los discursos al momento de pasar del medio fónico al gráfico dentro de una misma noticia multimedia de la publicación digital del diario El Comercio. Esto, como ya fue indicado, lo llevaré a cabo mostrando los cambios en la junción de los discursos. 
https://doi.org/10.46744/bapl.201902.005

Enfocaré el análisis en las estrategias de verbalización vinculadas con una construcción sintáctica producto de una mayor planificación propia de la comunicación por medio gráfico. Como señalé en los apartados anteriores, se espera que el diario El Comercio evidencie en la redacción de sus noticias características de la distancia comunicativa, debido a las tradiciones discursivas que le competen; a su vez, también los discursos fónicos de las noticias, por las condiciones en que estas entrevistas han sido elaboradas, se han llevado a cabo en situaciones de distancia comunicativa. Sin embargo, debido a la naturaleza de lo que implica manifestar una noticia por el medio gráfico, se puede ver cómo el cambio de medio de la noticia termina presentando más características afines al polo escritural del continuo concepcional. Esto último apoya lo propuesto en la presente investigación: la relación entre el medio y la concepción de los discursos es mayor de lo que Koch y Oesterreicher proponen. Los análisis de las noticias presentadas a continuación nos brindarán evidencias para defender los planteamientos del presente trabajo. Es importante tener en cuenta que esta es una muestra de solamente seis noticias. En total, de las 71 noticias revisadas, 15 de ellas evidenciaron cambios en la junción. Esta cifra es solo una parte de las 46 noticias en las que se hallaron cambios en distintos fenómenos sintácticos al momento de pasar del medio fónico al medio gráfico.

\section{Noticia 1.}

Título: «Las AFP proponen plan para recobrar aportes impagos del Estado»

Fecha: viernes 16 de mayo de 2014

URL: http://elcomercio.pe/economia/peru/aafp-propone-planrecobrar-aportes-impagos-estado-noticia-1729895? ref = portada archivo\&ft=flujo_archivo_2014-05-16\&e=titulo_10

- Transcripción del discurso emitido a través del medio fónico (1a): Es mucho más fácil para el Gobierno en este momento hacer la parte del gobierno central

(1b): pero tenemos que sentarnos con los gobiernos regionales y con los gobiernos municipales 
(1c): porque diríamos ellos son diríamos los que tienen más deudas

- Texto del discurso emitido a través del medio gráfico $(1 \mathrm{~A})$ «Es mucho más fácil para el Gobierno en este momento ver la parte de gobierno central. Pero [también] tenemos que sentarnos con los gobiernos regionales y con los gobiernos municipales porque diríamos que ellos son los que tienen más deuda».

En la noticia 1, se puede ver un cambio sintáctico en el paso del código fónico al gráfico. En primer lugar, se muestra en (1A) una formulación más condensada y compacta del discurso, propia de los discursos afines a los discursos escriturales. En (1c), se identifica el uso del marcador discursivo conversacional diríamos; este aparece desvinculado de la sintaxis de la oración, es decir, como un enlace extraoracional. Aquí llama la atención el modo en que se incorporó dicho elemento en la sintaxis de (1A). Así pues, puede notarse en (1A) que, como estrategia de escrituralización, se unió el verbo decir conjugado al enunciado incorporándolo sintácticamente. Este verbo pasó a ser el núcleo del predicado de la oración subordinada y se satisfizo, debido a sus propiedades transitivas, el argumento requerido. Por ello, se le agregó como objeto directo una proposición subordinada sustantiva introducida por la conjunción que. Debido a que se recurrió a la subordinación del verbo diríamos, se presenta una relación hipotáctica en (1A) a diferencia de lo que se presentó (1c). La noticia emitida por el medio gráfico se evidencia una mayor integración entre sus elementos en comparación con la emitida a través del medio fónico, ya que ha pasado de nivel 1, en que no hay ningún conector de tipo sintáctico, de los grados propuestos por Raible al nivel 4, en el cual hay relación causal expresada por una conjunción subordinante.

\section{Noticia 2.}

Título: Laub: «Hay doble tributación por el impuesto a las ganancias de capital»

Fecha: martes 10 de diciembre de 2013 
https://doi.org/10.46744/bapl.201902.005

URL: http://elcomercio.pe/economia/mercados/laub-hay-dobletributacion-impuesto- ganancias-capital-noticia-1671322.

- Transcripción del discurso emitido a través del medio fónico (2a): Hay una doble tributación, si quieres, en la ganancia de capital

(2b): ¿Por qué? porque si a las empresas les va bien, pagas el $30 \%$ de impuesto a la renta

(2c): Y si el valor de las empresas aumenta, lo que estás diciendo, las utilidades de las empresas en el futuro van a ser mayores y van a pagar más impuestos

(2d): Entonces, estoy pagando un impuesto sobre otro impuesto

(2e): Entonces, estamos en una desventaja con Colombia y con Chile

- Texto del discurso emitido a través del medio gráfico (2A) «Hay doble tributación por la ganancia de capital. Si a las empresas les va bien, pagas el $30 \%$ de Impuesto a la Renta, y si el valor de las empresas aumenta, lo que estás diciendo es que las utilidades van a aumentar y van a pagar más impuestos en el futuro. Entonces, estoy pagando un impuesto sobre otro impuesto y estamos en una desventaja con Colombia y Chile», lamentó.

En (2A) hay una mayor integración de los elementos que forman parte del enunciado emitido por el medio fónico. En primer lugar, en el discurso por el medio gráfico, no hay informaciones complementarias desligadas de la sintaxis oracional, lo que sí sucede en (2a) con el uso de si quieres. En segundo lugar, no se presentan diálogos intrapersonales, como se ve en (2b), en donde el hablante se formula una pregunta a sí mismo y la responde; este es un rasgo discursivo muy de oralidad. En tercer lugar, en (2c) también se presenta un comentario externo de la sintaxis oracional del discurso emitido: lo que estás diciendo. Sin embargo, en el cambio de medio, esta intervención se incluye en la estructura oracional ligándose al 
verbo principal, similar a lo desarrollado en el análisis de la NOTICIA 1. En cuarto lugar, (2d) y (2e) se unen por un elemento explícito de unión sintáctica: la coordinación y en (2A), lo cual significa que, respecto de los niveles propuestos por Raible, se pasa del nivel 1 al nivel 3.

\section{Noticia 3.}

Título: «El sector privado sin apoyo del Estado no logrará la transformación educativa»

Fecha: jueves 5 de diciembre de 2013

URL: http://elcomercio.pe/economia/peru/sector-privadosin-apoyo-estado-no-lograra-transformacion-educativanoticia-1668899.

- Transcripción del discurso emitido a través del medio fónico (3a): En ese sentido se necesita diría yo mayor comunicación

- Texto del discurso emitido a través del medio gráfico $(3 \mathrm{~A})$ «En ese sentido, diría yo que lo que se necesita es mayor comunicación», postuló.

En el paso del medio fónico al gráfico de la presente noticia, se evidencia un incremento en el grado de integración de los enunciados. En este caso, la relación sintáctica pasó de paratáctica a hipotáctica. Esto se llevó a cabo utilizando el juntor que (el que se encuentra precedido por el pronombre yo), el cual funciona como nexo subordinante; ello generó una proposición subordinada sustantiva. Por otro lado, el que de relativo que se encuentra luego del pronombre lo fue incorporado en el proceso de escrituralización, lo cual también demuestra una mayor integración, ya que este refiere a un complemento oracional expreso luego del verbo copulativo.

En (3a), la expresión diría yo se encuentra totalmente desligada de la sintaxis oracional: es una información complementaria que interrumpe el enunciado, ya que se encuentra aislada de la estructura oracional del texto. Podría ser tomada como un marcador discursivo. Respecto de ello, 
en el paso del código fónico al gráfico, el redactor consideró oportuno insertar dicha expresión en el contexto oracional, ya que de ese cambio resulta una estructura más integrada. Este cambio es similar al analizado en la Noticia 1; es decir, se dio un paso del nivel 1 de Raible, en el que caracteriza a enunciados enlazados solo por yuxtaposición, al nivel 4, en el que se evidencia ya una integración por subordinación.

\author{
Noticia 4. \\ Título: «Creatividad Empresarial premiará propuestas de \\ impacto social» \\ Fecha: martes 5 de agosto de 2014 \\ URL: http://elcomercio.pe/economia/peru/creatividad- \\ empresarial-premiara-propuestas-impacto-social-noticia- \\ 1747616 ? ref $=$ flujo_tags_331291\&ft $=$ nota_10\&e $=$ titulo? ref $=$ \\ nota_economia\&ft $=$ mod_leatambien\&e $=$ titulo
}

- Transcripción del discurso emitido a través del medio fónico (4a): Responsabilidad social podría ser el marco general, el marco teórico

(4b): A nosotros nos gusta el concepto de compromiso porque es más allá, es voluntario

(4c): Son organizaciones, empresas, instituciones, ONG, asociacionesquemiran problemas realesdecompatriotas nuestros (4d): Y no se quedan pasivos

- Texto del discurso emitido a través del medio gráfico (4A) «Está dentro del marco [de responsabilidad social]; pero, más que ello, nos gusta el concepto de compromiso porque las iniciativas son voluntarias por parte de empresas, asociaciones, ONG, que miran problemas reales y no se quedan pasivas».

En (4A), se presenta una mayor integración de los elementos que conforman el enunciado en relación con cómo se han vinculado dichos elementos en el discurso emitido en el video, por medio fónico. En el discurso fónico emitido por el entrevistado, no se integran los enunciados de (4a) y (4b): estos son planteados como oraciones independientes. Sin 
embargo, en (4A) el redactor optó por pasar de una simple yuxtaposición a relacionar, a partir del elemento explícito pero, los enunciados. Esto ha unido sintácticamente ambas oraciones por coordinación, ya que ambas siguen presentando verbo principal conjugado (el primero es está y el segundo es gusta). Respecto de la escrituralización aquí presentada, se está pasando del nivel 1 al nivel 3 de Raible.

Asimismo, también se puede observar la integración que llevó a cabo el redactor al reducir la cantidad de verbos sueltos luego del conector subordinante porque en ( $4 \mathrm{~b})$. En el enunciado manifestado por medio fónico, podemos encontrar dos veces el verbo es en ( $4 \mathrm{~b})$ y una vez el verbo son en (4c). Esta recurrencia de verbos copulativos ha sido eliminada al pasar del medio fónico al gráfico. En (4A) quien redacta optó por presentar solo un verbo copulativo integrando los enunciados fragmentados del discurso por vía fónica a una misma unidad sintáctica, lo que dio como resultado un discurso con mayor integración. Entonces, el atributo del verbo copulativo son fue solo el adjetivo voluntarias y, así, los términos restantes quedaron con la función de complementar los actantes requeridos por el verbo.

Por otro lado, en este ejemplo también se puede ver un cambio en la concordancia al pasar del medio fónico al gráfico. En (4d), el adjetivo pasivos no guarda concordancia con los sustantivos a los cuales modifica, ya que está modificando a sustantivos plurales femeninos. Por ello, en (4A) se optó por realizar el cambio de género gramatical: el término pasivas sí guarda una concordancia de acuerdo con la exigida por la gramática normativa.

\section{Noticia 5.}

Título: «Calidad en telecomunicaciones pasa por mejoras en supervisión»

Fecha: viernes 16 de mayo de 2014

URL: http://elcomercio.pe/economia/peru/osiptel-subirmultas-mejorara-servicios-telecomunicaciones-noticia1729662 ?ref =portada_archivo\&ft=flujo_archivo_2014-05$16 \& \mathrm{e}=$ titulo_12. 
https://doi.org/10.46744/bapl.201902.005

- Transcripción del discurso emitido a través del medio fónico (5a): Sin embargo, este es un mecanismo sancionador que maneja el Osiptel

(5b): y no debe confundirse con el procedimiento que maneja el Ministerio de Transportes para la evaluación de decidir si es que le va a renovar el contrato a una empresa o no

- Texto del discurso emitido a través del medio gráfico $(5 \mathrm{~A})$ «[...] Sin embargo, este mecanismo sancionador no debe confundirse con el procedimiento que maneja el Ministerio de Transportes para la evaluación para decidir si le va a renovar el contrato a una empresa o no».

En $(5 A)$, se puede observar un nivel muy alto de integración en el paso del medio fónico al gráfico. Por un lado, los enunciados (5a) y (5b) se encuentran vinculados a través de la conjunción $y$, lo cual evidencia un grado de integración de nivel 3. Aquí, hay una relación explícita entre los enunciados; sin embargo, al ser ambas cláusulas oraciones principales, se sigue estando frente a un procedimiento paratáctico. Por otro lado, al momento de graficar la misma noticia, se lleva a cabo un procedimiento claramente hipotáctico, ya que en $(5 \mathrm{~A})$ se terminaron distribuyendo los roles sintácticos de tal manera que $(5 \mathrm{a})$ y $(5 \mathrm{~b})$ pasaron a formar parte de una misma oración principal, en la cual hay sujeto, predicado y complementos. Esto se realizó nominalizando (5a), lo cual lo vinculó estrechamente con (5b). Con ello, se llegó al nivel máximo de integración en (5A).

\section{Noticia 6. \\ Título: «Pro inversión: Cartera de proyectos supera los US\$ 3000 mlls» \\ Fecha: martes 6 de octubre de 2015 \\ URL: http://elcomercio.pe/economia/peru/pro-inversion-cartera- proyectos-supera-us3000-mlls-noticia-1846332? ref= portada archivo\&ft=flujo_archivo_2015-10-06\&e=titulo_6.}

- Transcripción del discurso emitido a través del medio fónico (6a): Los proyectos peruanos se benefician de dos cosas, ¿no? 
https://doi.org/10.46744/bapl.201902.005

(6b): Uno, de tener un Gobierno con un respaldo fiscal importante y un crédito crediticio importante, ino? (6c): Y dos porque son proyectos que ya son conocidos, ¿no? son proyectos que tienen mecanismos que ya son conocidos por más de diez años

- Texto del discurso emitido a través del medio gráfico (6A) «Los proyectos peruanos se benefician porque tienen un Gobierno con respaldo fiscal importante y crediticio y porque son proyectos ya conocidos, que tienen mecanismos conocidos por más de 10 años».

En (6A), hay un proceso de integración respecto de la noticia emitida por el medio fónico; se ha llegado al nivel 4 de los propuestos por Raible, lo cual conlleva una relación hipotáctica. Esto se logró uniendo (6a) con (6b) por subordinación; en este procedimiento, el infinitivo tener pasó a ser un verbo conjugado subordinado a partir de la partícula porque introducida en (6A). Asimismo, en (6A) la enumeración de los dos factores por los cuales se benefician los proyectos peruanos son parte de una misma oración integrada sintácticamente: hay dos subordinadas dentro de una misma oración principal.

Además, el uso del relativo que en (6A) suplantó la frase son proyectos, la cual redunda (rasgo propio de los discursos orales) en (6c) a pesar de también presentar el elemento relativo.

Más allá de ello, se evidencia una producción más compacta en (6A) por hacer el cambio de la subordinada adjetiva que ya son conocidos, por el empleo de una sola palabra que cumple la misma función oracional: conocidos. Esto es una característica de la condensación típica de los discursos de concepción escritural.

\section{Conclusiones}

Con el análisis de las noticias presentadas, se ha podido demostrar que, al cambiar de un medio a otro, se ha aumentado el nivel de integra- 
https://doi.org/10.46744/bapl.201902.005

ción de los enunciados. Esto, en algunos casos, implica que las relaciones paratácticas se vuelvan hipotácticas. Así pues, los redactores realizaron algunos cambios respecto del discurso original valiéndose de estrategias de junción que incrementaron el nivel de integración de los discursos. Con ello, lograron colocar mayor información en una misma unidad de idea a través de distintos métodos: subordinación; añadir algún conector explícito; posicionar nuevos argumentos respecto del verbo principal, como los complementos directos o indirectos; agregar complementos adjuntos, circunstanciales, a la predicación principal; entre otros. Estos cambios han ocasionado que la concepción del discurso sufra alteraciones: la concepción del discurso emitido a través del medio gráfico ha pasado a ser incluso más afín a las características escriturales de lo que era la noticia emitida por medio fónico.

La habilidad lingüística de los redactores para vincular proposiciones es evidente. Esto no significa que quienes fueron entrevistados no posean dicha habilidad: esta distinción se encuentra justificada por la diferencia entre ambas circunstancias comunicativa, entrevista fónica versus redacción gráfica. Sería inadecuado considerar que el estilo de los discursos emitidos por el medio fónico no ha sido cuidado. Al contrario, teniendo en cuenta cómo categoriza Vigara Tauste (1992) las entrevistas, se presume, incluso, cierta planificación previa; ya que el entrevistado es consciente del papel que el diario El Comercio juega para sus lectores $y$, en general, para la sociedad. Sin embargo, teniendo en cuenta las características propias de la creación de un discurso mientras se comparte el espacio, el tiempo y la situación con el interlocutor, y las de uno en las que el emisor se encuentra aislado con la posibilidad de organizar sus ideas más organizadamente es lo que hace que el producto de la comunicación por el medio gráfico resulte, en la mayoría de los casos, más integrado, así como, en muchos casos, más condensado.

Podemos concluir, también, que la situación caracterizada por las publicaciones en el formato digital de El Comercio no llega a producir cambios significativos respecto de lo esperable en un discurso tradicional trasmitido a través de la versión impresa. No obstante, sí cabe la posibilidad de que, con el paso del tiempo, dicha relación pueda variar. 
En suma, he tenido como principal objetivo mostrar, a partir de mecanismos concretos de junción en la configuración de los discursos, el impacto que tiene el medio en la concepción de estos últimos, lo cual permite confirmar que la relación entre ambos aspectos es bastante estrecha. Así pues, he querido aportar evidencia sobre cómo el medio influye en la elaboración y, por consiguiente, en la concepción de los discursos por las características propias del contexto situacional en los que se encuentran inmersos tanto aquellos que se manifiestan por el medio gráfico como los que se realizan a través del medio fónico. Esto se debe a que todo redactor organiza y construye su texto en forma de acuerdo con los requerimientos de las condiciones comunicativas concretas en las que se encuentra.

Considero que los motivos más importantes de los cambios son dos principalmente. En primero lugar, los redactores tienen la posibilidad de planificar con más tiempo su discurso por no compartir contexto comunicativo con sus interlocutores y, en segundo lugar, los redactores tienen la posibilidad de corregir sus textos si pueden elaborarlos de modo más claro. Ellos muestran la posibilidad de llevar a cabo un proceso de condensación y síntesis que, en muchos casos, en la comunicación por el medio fónico no es posible. Esto también pudo estar motivado, en general, por las tradiciones discursivas propias de las notas periodísticas de El Comercio, las cuales requieren de la mayor precisión y determinación al momento de emitir el mensaje.

Espero que la comparación y análisis aquí realizados puedan servir para la investigación lingüística, en tanto puede ser un punto de partida para la matización y reformulación de las relaciones previamente establecidas entre el medio y la concepción respecto de los planteamientos de Koch y Oesterreicher (2007). Esto se debe a que la dependencia entre el medio y la concepción de los discursos es mayor que la reconocida por ambos autores en su trabajo sobre el tema. Ellos se habían enfocado particularmente en la influencia de las situaciones comunicativas para la configuración de los discursos, lo que ocasionó que se tome una importancia solo muy relativa al medio. 


$$
\text { https://doi.org/10.46744/bapl.201902.005 }
$$

Finalmente, el análisis de los distintos tipos de texto puede ayudar para estudios vinculados con la bistoria de la lengua, ya que puede ayudar a explicar los motivos vinculados con su evolución. Esto lo sostengo a partir de la siguiente afirmación de Johannes Kabatek: «La historia de la lengua se concibe como historia de los medios de comunicación en sentido amplio. Es de suma importancia la diferencia entre comunicación oral o escrita, entre la cultura del manuscrito y la cultura del libro, entre la lengua con apoyo institucional o sin él» (2003: 38). 
https://doi.org/10.46744/bapl.201902.005

\section{BIBLIOGRAFÍA}

BOND, F. (1965). Introducción al periodismo: estudio del cuarto poder en todas sus formas. México D. F.: Limusa.

EL COMERCIO (1997). La huella del decano. Lima: Empresa Editora El Comercio S. A.

FAIRCLOUGH, N. (1992). Discourse and Social Change. Cambridge: Polity Press.

GARGUREVICH, J. (1989). Géneros periodísticos. La Habana: Pablo de la Torriente.

HERNÁNDEZ, Ú. (2017). El paso del medio fónico al medio gráfico: análisis sintáctico de la escrituralización de noticias en la publicación digital del diario El Comercio. Tesis para optar el grado de magíster en Lingüística. Lima, Pontificia Universidad Católica del Perú.

JUNGBLUTH, K. (1996). «El carácter de los textos semi-orales y el juntor que». En Oesterreicher/ Stoll /Wesch (Eds.). Competencia escrita, tradiciones discursivas y variedades lingǘstica. Aspectos del español europeo y americano en los siglos XVI y XVII. Tübingen: Gunter Narr Verlag, 339-358.

KABATEK, J. (2003). «La lingüística románica histórica: Tradición e innovación en una disciplina viva». La Corónica. Volumen 31, número 2, 35-40.

KOCH, P. y OESTERREICHER, W. (2007). Lengua hablada en la Romania: español, francés, italiano. Madrid: Gredos.

LÓPEZ, Á. (2000). «Relaciones paratácticas e hipotácticas». En DEMONTE, Violeta e Ignacio BOSQUE (Coord.). Gramática 
https://doi.org/10.46744/bapl.201902.005

descriptiva de la lengua española. Volumen 3. Madrid: Espasa, 3507-3548.

OESTERREICHER, W. (1997). «Pragmática del discurso oral». En Berg, Walter Bruno/ Schaffauer, Marcus Klaus (editores). Oralidady Argentinidad. Estudios sobre la función del lenguaje hablado en la literatura argentina. Tubingen: Gunter Narr, 88-97.

. (1994). «El español en textos escritos por semicultos. Competencia escrita de impronta oral en la historiografía indiana (s. XVI)». En Jens Lüdtke (comp). El español de América en el siglo XVI. Berlin: Iberoamericana, pp. 155-190.

RAIBLE, W, (2001). Linking clauses. Friburgo de Brisgovia: Universidad de Friburgo. Consulta: 17 de diciembre de 2014.

. (1992). Junktion. Eine Dimension der Sprache und ibre Realisierungsformen zwischenAggregation und Integration, Heidelberg, Winter (=Sitzungsberichte der Heidelberger Akademie der Wissenschaften. Philosophisch-historische Klasse, Jahrgang 1992, Bericht 2).

RENWICK, R. (2006). «En torno a la junción como dimensión universal del lenguaje». Lexis. Lima, Vol. XXX, 2, 273-2790.

. (2002). «Hacia una clasificación concepcional de cuatro textos de la Historiografía del Amazonas (s. XVI). Las relaciones de Pedro de Monguía, Pedriarias de Almesto, Gonzalo de Zúñiga y Francisco Vásquez». Lexis. Lima, Vol. XXVI ,1, 181-205.

. (1997). «El proyecto de investigación "Escritura de impronta oral en la historiografía colonial de Hispanoamérica (1500-1615)" (Universidad de Friburgo). Fundamen- 
https://doi.org/10.46744/bapl.201902.005

tos teóricos y metodología». Lexis. Lima, Vol. XXI, 1, $17-52$.

- (1996). «Recursos de integración sintáctica en la Relación de Pedro de Monguía». En Oesterreicher/ Stoll /Wesch (eds.). Competencia escrita, tradiciones discursivas y variedades lingüística. Aspectos del español europeo y americano en los siglos XVI y XVII. Tübingen: Gunter Narr Verlag, 269-292.

VIGARA TAUSTE, A. (1992). Morfosintaxis del español coloquial. Esbozo estilístico. Madrid: Gredos. 